\title{
Laparoscopic transhiatal suture and gastric valve as a safe and feasible treatment for Boerhaave's syndrome: an Italian single center case series study
}

\author{
A. Veltri ${ }^{1,2^{*}}$ (D) J. Weindelmayer ${ }^{2}$, L. Alberti ${ }^{2}$, C. A. De Pasquall ${ }^{2}$, M. Bencivenga ${ }^{2}$ and S. Giacopuzzi ${ }^{2}$
}

\begin{abstract}
Background: Boerhaave's syndrome (BS) is a rare life-threating condition with poor prognosis. Unfortunately, due to its very low incidence, no clear evidences or definitive guidelines are currently available: in detail, surgical strategy is still a matter of debate. Most of the case series reports thoracic approach as the most widely used; conversely, transhiatal abdominal management is just described in sporadic case reports. In our center, the laparoscopic approach has been adopted for years: in the present study, we aim to show his feasibility by reporting the outcomes of the largest clinical series available to date.

Methods: Clinical records of patients admitted for BS to the General and Upper GI Surgery Division of Verona from February 2014 to December 2019 were retrospectively collected. Clinico-pathological characteristics, preoperative workup, surgical management, and outcomes were analyzed.

Results: Seven patients were admitted; epigastric/thoracic pain and vomiting were the most frequent symptoms at diagnosis. Laboratory findings were not specific; conversely, radiological imaging always revealed abnormal findings: particularly, CT had excellent sensitivity in detecting signs of esophageal perforation. All but one case had diagnostic workup and received surgery within $24 \mathrm{~h}$. Every patient had laparoscopic transhiatal direct suture and gastric valve; 2 patients (28.6\%) also needed a thoracoscopic toilette. Postoperative complications occurred in 4 patients (57\%), but in only two of them (29\%), the complication was severe according to Clavien-Dindo classification (both received thoracentesis or thoracic drainage for pleural effusion). Of note, no cases of postoperative esophageal leak were recorded. Postoperative mortality was $14 \%$ due to one patient who died for cardiovascular complications. Most of the patients (71.4\%) were admitted to ICU after surgery (average length, 8.8 days); mean hospital stay was 14.7 days. No patients had readmissions.

(Continued on next page)
\end{abstract}

\footnotetext{
* Correspondence: alessandro.veltri85@gmail.com

${ }^{1}$ General and Upper GI Surgery Division, Azienda Ospedaliera Universitaria Integrata, Piazzale A. Stefani, 1, 37126, Verona, Italy

2Upper G.I. Surgery Division, Department of General Surgery, University of Verona, 37126 Verona, Italy
}

(c) The Author(s). 2020 Open Access This article is licensed under a Creative Commons Attribution 4.0 International License, which permits use, sharing, adaptation, distribution and reproduction in any medium or format, as long as you give appropriate credit to the original author(s) and the source, provide a link to the Creative Commons licence, and indicate if changes were made. The images or other third party material in this article are included in the article's Creative Commons licence, unless indicated otherwise in a credit line to the material. If material is not included in the article's Creative Commons licence and your intended use is not permitted by statutory regulation or exceeds the permitted use, you will need to obtain permission directly from the copyright holder. To view a copy of this licence, visit http://creativecommons.org/licenses/by/4.0/ The Creative Commons Public Domain Dedication waiver (http://creativecommons.org/publicdomain/zero/1.0/) applies to the data made available in this article, unless otherwise stated in a credit line to the data. 


\begin{abstract}
(Continued from previous page)
Conclusions: To our knowledge, this is the largest case series reporting laparoscopic management of BS. We show that laparoscopy is a safe and feasible approach associated with a shorter length of hospital stay when compared with clinical series in which thoracic approach had been chosen. Of note, laparoscopic management would be easily adopted by surgical centers treating benign gastro-esophageal junction entailing a proper management more widely.
\end{abstract}

Keywords: Boerhaave's syndrome, Spontaneous esophageal rupture, Esophageal perforation, Laparoscopy, Transhiatal approach, Direct suture closure, Gastric valve

\section{Background}

Boerhaave's syndrome (BS) has been firstly described by Herman Boerhaave, a Dutch clinician and professor from Leida's University in 1724. In "atrocis, nec descripti prius, morbi historia," he told the death of Baron van Wassenaer: after a large meal, he started vomit, and then it revealed the typical clinical picture of BS with acute onset of chest pain, dyspnea, cyanosis, and subcutaneous emphysema; the exitus occurred in $24 \mathrm{~h} \mathrm{[1]}$.

Currently, BS and more generally esophageal perforations are considered as catastrophic conditions, often life-threatening, with 10 to $40 \%$ mortality rates (even higher rates are reported in septic patients with spontaneous perforations) [2]. Due to its very low incidence and aspecific features, more than $50 \%$ of cases are misdiagnosed, with a subsequent delay in treatment $[3,4]$.

Nowadays, there is no standard therapeutic strategy, and similarly, there are no specific guidelines for surgery. Nevertheless, the aim of the treatment should be both repair the esophageal tear and control the mediastinal contamination: on these bases, different strategies have been proposed. The most diffuse approach is the surgical direct repair with placement of a thoracic drainage: recently, less invasive approaches have been suggested such as conservative and endoscopic treatments, but there are only a few case series reporting discouraging or inconstant results [5-7]; thus, at the moment, surgery remains the cornerstone of BS management.

Timing of surgery is still a matter of discussion: most authors suggest that it should be taken within $24 \mathrm{~h}$ of onset; however, some papers suggest that the length of time elapsed would not affect outcomes after surgery [4, 8-10].

As regards the type of surgical approach, thoracotomy is the most frequently chosen approach even if in literature there are several studies reporting transhiatal management as much as safe [11-13]. In our department, transabdominal approach is routinely adopted to treat BS.

The aim of this case series is to report postoperative outcomes of a series of patients with BS treated by laparoscopic approach. We also compared our results with those of trans-thoracic strategy as described in literature.

\section{Methods}

Clinical data

We retrospectively collected clinical records of patients admitted with the diagnosis of spontaneous esophageal perforation and surgically treated from February 2014 to December 2019 to the General and Upper GI Surgery Division of Verona. Demographic characteristics, clinical presentation, time between the onset of symptoms, and surgery as well as preoperative blood test and radiological management were analyzed. Postoperative clinical assessment and radiological (contrast X-ray)/endoscopic re-evaluations were described; duration of hospital stay, 30-day morbidity (according to Clavien-Dindo classification), and mortality were taken into account as treatment outcomes.

\section{Surgical procedure}

When BS is suspected, we proceed to video-laparoscopic exploration. The surgeon is placed between the patient's legs while assistant is on the left side of the patient; the patient is placed in a $20-30^{\circ}$ reverse-Trendelenburg position. After creation of pneumoperitoneum with open access technique, we insert the first 12-mm blunt trocar halfway between the xiphoid process and the umbilicus. Then, we place four additional trocars: a 5-mm trocar is inserted below the costal margin on the right side of the patient, on the right midclavicular line; a $12 \mathrm{~mm}$ trocar is placed symmetrically on the left side; a $5-\mathrm{mm}$ trocar is inserted on the left anterior axillary line, $2-3 \mathrm{~cm}$ above the anterior superior iliac spine; finally, through a $3-\mathrm{mm}$ incision below the xiphoid process, we place a Nathanson liver retractor (Fig. 1).

With the left hepatic lobe raised, we divide the Laimer-Bertelli membrane to expose the diaphragmatic pillars and the esophageal anterior wall to explore it and recognize the laceration. On-call endoscopist performs intraoperative esophagogastroscopy: this combined approach allows us not only to recognize the laceration when it is not clearly viewable but also to establish the length of the tear with more accuracy.

After detection of the esophageal lesion, we directly repair it: the first stich is performed on the superior edge of the laceration, and then, we realize a continuous 


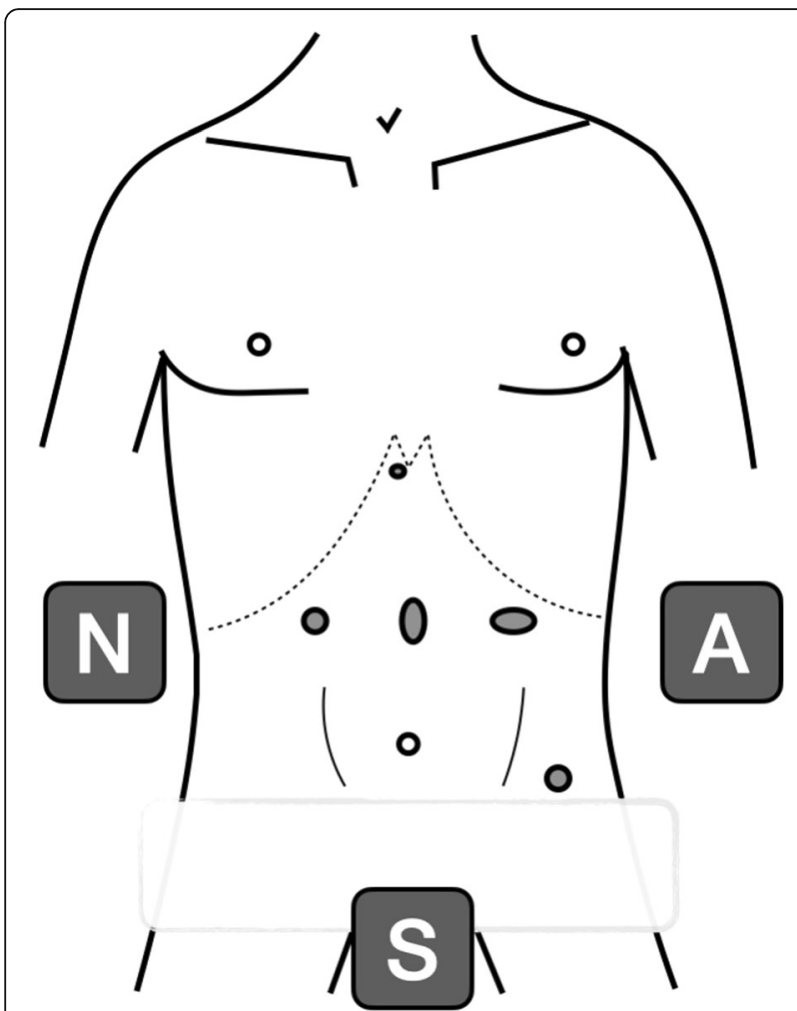

Fig. 1 Insertion of the first 12-mm blunt trocar halfway between the xiphoid process and the umbilicus and the four additional trocars

suture to close it. We do not clear the edges of esophageal defect before repairing it; in our opinion, this is an unnecessary procedure: if patient receives surgery promptly, the edges are still vital, and debridement would waver in enlargement of the lesion.

Subsequently, we reinforce the suture with a gastric valve: we rotate the anterior surface of greater curvature over the suture after division of 2-3 short gastric vessels; we fixed valve with 3 absorbable stitches: first at the esophagus, cranially to the suture; then, a symmetrical one on the lower margin of the valve, almost reaching the lesser curvature; finally, a stich between the left side of the valve and the left diaphragmatic pillar.
We usually perform transhiatal lavage of abdominal and thoracic cavities: only in selected and challenging cases, we also perform a thoracic lavage through thoracotomy/thoracoscopy. Finally, we always place a closed passive abdominal transhiatal drainage: subsequently, on the basis of the contamination pattern observed, we decide if more thoracic or abdominal drainages are necessary.

\section{Results}

Seven patients were admitted for BS in our dedicated surgical unit (Table 1): of these, 6 were male, and 1 was female; the age range was 37-86 years, with an average of 62.1 years. The most common clinical presentation included postprandial epigastric/thoracic pain and vomiting (86\%); other symptoms and signs such as dyspnea, fever, and syncope were less frequent $(<15 \%$ each). No one had clear subcutaneous emphysema or hematemesis. Laboratory findings of leukocytosis were fluctuating: $57 \%$ had leukocytosis, $14 \%$ had leukopenia whereas others patients had a normal white blood cells count; on the contrary, radiological imaging revealed abnormal findings in all cases: in detail, all patients received an urgent thoracoabdominal CT always describing at least one finding of perforation such as pneumomediastinum or soft tissue emphysema.

Within $24 \mathrm{~h}$ from the onset of symptoms, all cases but one had diagnostic workup and received surgery (Table 2): every patient was suitable for laparoscopic transhiatal direct suture and subsequent gastric valve; 2 patients $(28.6 \%)$ also needed a thoracoscopic lavage. Thoracic and/or abdominal drainages have been always put on the basis of the operative findings (as summarized in Table 2). Accordingly, surgical time ranged widely (75-214 $\mathrm{min}$; average of $154 \mathrm{~min}$ ).

Five patients (71.4\%) were admitted to ICU where, on the average, they spent 8.8 days (2-15 days); average length of hospital stay was of 14.7 days (7-28 days). No patients had readmissions.

Noteworthy, no patient had suture leakage; most of them (57.1\%) had at least one postoperative

Table 1 Patients characteristics and clinical outcomes

\begin{tabular}{|c|c|c|c|c|c|c|c|c|c|c|}
\hline Patient & Age & ER admission & Clinical picture & $\begin{array}{l}\text { Date of } \\
\text { operation }\end{array}$ & $<24 h$ & $\begin{array}{l}\text { Postop } \\
\text { stay }\end{array}$ & Postop IV & ICU stay & $\begin{array}{l}\text { Swallow } \\
\text { X-rays (POD) }\end{array}$ & LOS (Days) \\
\hline B.A. & 57 & $18 / 02 / 2014$ & Pain and vomit & $19 / 02 / 2014$ & Yes & Ward & No & - & 3 & 7 \\
\hline L.C. & 37 & $31 / 05 / 2014$ & Pain & 01/06/2014 & Yes & Ward & No & - & 5 & 13 \\
\hline B.G. & 66 & 08/12/2015 & Pain, vomit, and dyspnea & 08/12/2015 & Yes & $\mathrm{ICU}$ & ET (removed I POD) & 2 & 6 & 28 \\
\hline B.B. & 61 & 01/01/2017 & Pain, vomit, and syncope & 01/01/2017 & Yes & $\mathrm{ICU}$ & ET (removed XIII POD) & 15 & 17 & 22 \\
\hline R.U. & 54 & $17 / 11 / 2017$ & Pain, vomit, and fever & 18/11/2017 & No & $\mathrm{ICU}$ & ET (removed I POD) & 4 & 9 & 10 \\
\hline D.Z. & 86 & $27 / 12 / 2017$ & Pain and vomit & $27 / 12 / 2017$ & Yes & $\mathrm{ICU}$ & $\mathrm{ET}$ & 11 & - & 11 \\
\hline P.A. & 74 & 06/12/2019 & Pain and vomit & 06/12/2019 & Yes & $\mathrm{ICU}$ & ET (removed X POD) & 12 & 11 & 12 \\
\hline
\end{tabular}

ER emergency room, ICU intensive care unit, $I V$ invasive ventilation, $E T$ endotracheal tube, $P O D$ postoperative day, LOS length of stay 
Table 2 Surgical data and postoperative complications

\begin{tabular}{|c|c|c|c|c|c|c|}
\hline Patient & Surgical operation & $\begin{array}{l}\text { Operation } \\
\text { time (min) }\end{array}$ & $\begin{array}{l}\text { Intraoperative } \\
\text { complications }\end{array}$ & Drains & $\begin{array}{l}\text { 30-day morbidity } \\
\text { (CD grade) }\end{array}$ & Readmission \\
\hline B.A. & $\begin{array}{l}\text { Laparoscopic transhiatal direct } \\
\text { suture and gastric valve }\end{array}$ & 127 & No & Abdominal & None & No \\
\hline L.C & $\begin{array}{l}\text { Laparoscopic transhiatal direct } \\
\text { suture and gastric valve }\end{array}$ & 165 & No & $\begin{array}{l}\text { Pleural, abdominal, and } \\
\text { intramediastinal }\end{array}$ & Fever (II) & No \\
\hline B.G. & $\begin{array}{l}\text { Laparoscopic transhiatal direct suture } \\
\text { and gastric valve; thoracoscopic lavage }\end{array}$ & 202 & No & $\begin{array}{l}\text { Pleural, abdominal, and } \\
\text { intramediastinal }\end{array}$ & $\begin{array}{l}\text { Fever and bilateral } \\
\text { pleural effusions (IIIA) }\end{array}$ & No \\
\hline B.B. & $\begin{array}{l}\text { Laparoscopic transhiatal direct suture } \\
\text { and gastric valve }\end{array}$ & 140 & No & Intramediastinal & Pleural effusion (IIIA) & No \\
\hline R.U. & $\begin{array}{l}\text { Laparoscopic transhiatal direct suture } \\
\text { and gastric valve }\end{array}$ & 155 & No & Abdominal & None & No \\
\hline D.Z. & $\begin{array}{l}\text { Laparoscopic transhiatal direct suture } \\
\text { and gastric valve; thoracoscopic lavage }\end{array}$ & 214 & No & Pleural and abdominal & $\mathrm{CHF}(\mathrm{V})$ & - \\
\hline P.A. & $\begin{array}{l}\text { Laparoscopic transhiatal direct suture } \\
\text { and gastric valve }\end{array}$ & 75 & No & Pleural & None & No \\
\hline
\end{tabular}

$C D$ Clavien-Dindo, CHF congestive heart failure

complication: 2 of them had fever for which antibiotic therapy was necessary; 2 patients had pleural effusion and subsequently thoracentesis (one of them also needs percutaneous drainage). Finally, one patient died for cardiovascular complications: nevertheless, he was an 86 years old man with a vulnerable condition and a history of cardiac disease. Moreover, even if the time passed between surgery and clinical manifestation was less than $24 \mathrm{~h}$, during the thoracoscopic exploration, we found an important contamination of the pleural space, and it was not directly accessible because of the extent of pleural adhesions: these findings may suggest that probably the esophageal rupture had realized longer before the onset of symptoms.

All survived patients received a gastrografin swallow radiography prior to remove nasogastric tube and start refeeding (average of 8.5 days; range 3-17 days); after the intraoperative upper GI endoscopy, no other endoscopic procedures were needed during the postoperative course.

All the patients received a gastrografin swallow radiography 3 months after discharge: all of them showed regular outlines and motility of the esophagus and stomach. None of them required readmission or reoperations.

At last follow-up, all the dismissed patients were alive: the delay between surgery and last clinical follow-up ranged from 6 to 75 months (median 45.5 months). None of the patients reported dysphagia; only 1 patient complained seasonal symptoms of gastro-esophageal reflux, well responsive to PPI therapy.

\section{Discussion}

$\mathrm{BS}$ is a rare condition that occurs approximately 3.1 per $1,000,000 /$ year: it represents one of the most lethal disorders of the gastrointestinal tract, with mortality rates up to $40 \%$ and strongly associated with time elapsed between onset of symptoms and surgery [4, 6, 8]. It is the origin of $15 \%$ of esophageal perforations [14]: classically, the lesion is found on the left side of the lower third of the thoracic esophagus, and it may be large $(3-6 \mathrm{~cm})$ $[14,15]$; such perforations may lead to emphysema, mediastinitis, and septic shock. However, in the early phase, the clinical manifestations may be vague: indeed, the typical Mackler triad of pain, vomit, and subcutaneous emphysema is present in only half of the cases [8, 16]; all this makes challenging the differential diagnosis. In our case series, we collected similar data: as aforementioned, clinical presentation was usually unclear and ambiguous, so further investigations were constantly necessary.

Despite thoracic X-ray usually shows alterations compatible with BS, often it is not specific and could not rule out the esophageal perforations whenever it could be negative [8]. Theorically, the imaging technique of choice should be the contrast swallow radiography (gastrografin) that is highly sensitive even for small esophageal perforations: in our experience, CT scan was always preferred due to organizational difficulties in emergency setting but, despite that, it has proved to have excellent sensitivity in detecting direct or indirect signs of esophageal perforation (extraluminal air bubbles or esophageal wall thickening); moreover, computed tomography allowed to reach a detailed assessment of the involved organs (Figs. 2 and 3). No less importantly, various papers stated that it can be also very helpful in differential diagnosis and eliminate conditions that may confound the clinician $[3,4]$.

Facing BS, emergency surgery is the treatment of choice: several studies had demonstrated that the time elapsed is crucial for prognosis and had identified the first $24 \mathrm{~h}$ as the golden time to better outcomes [4, 8, 11 ; nonetheless, further authors reported good results 


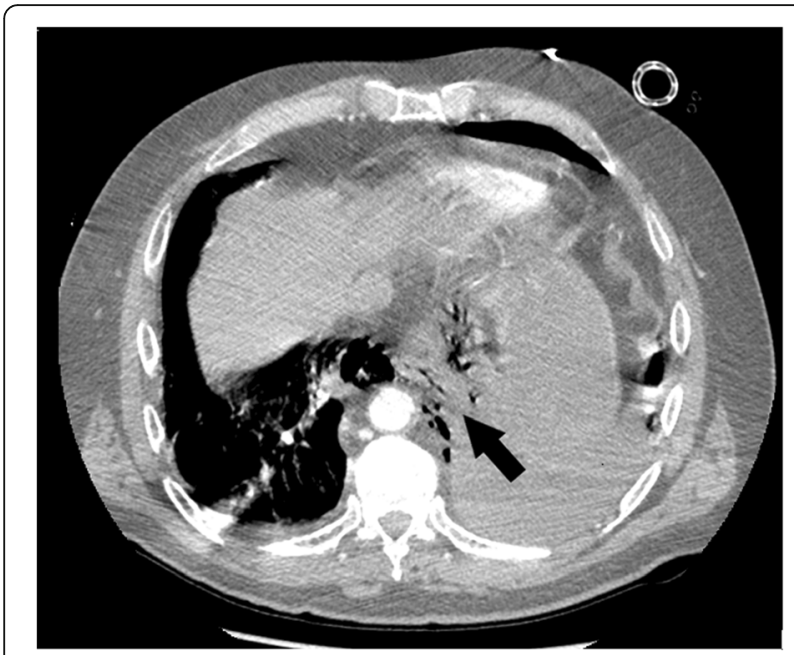

Fig. 2 Computed tomography chest revealed gas bubbles laterally to the gastro-esophageal junction (arrow). Axial view

even if surgery is delayed. Our case series supports this latter evidence: only one patient received surgery after $24 \mathrm{~h}$, but he had a non-complicated postoperative course, and he was discharged after 10 days without postoperative complications.

Which is the best way to approach BS is still a matter of debate: actual guidelines for thoracic esophageal perforation suggest an individualized approach to primary repair the tear, while for what concern specifically esophageal spontaneous rupture, most of the available studies considered the thoracotomy/thoracoscopic approach as the way of choice $[9,17-21]$. Anyway, there is not any specific guidelines for BS: some case reports suggest that laparoscopy may be just as safe and effective $[12,13]$; lastly, some authors also reported conservative or endoscopic treatment: nevertheless, these are just a few studies involving patients with less severe clinical

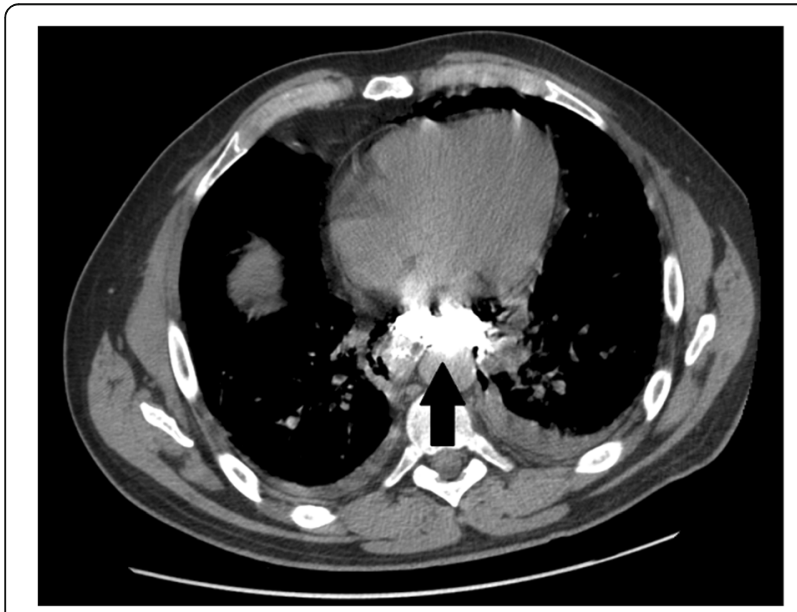

Fig. 3 Computed tomography chest demonstrated extraluminal contrast extending into the mediastinum (arrow). Axial view picture, so further researches are needed to better understand their feasibility in more challenging conditions $[5,7]$. In this case series, we present our 5 years' experience: in all patients, we choose to approach laparoscopically the esophageal tear; when necessary, afterwards we performed a thoracic lavage through left thoracotomy. In our opinion, the transhiatal approach offers various advantages. First, it allows to have a direct and clearer assessment of cardias exploring both abdominal and distal thoracic esophagus: furthermore, whenever thoracic contamination would not be manageable transhiatally, a less wide access to thorax would be quite enough to explore and drain it; moreover, the gastric valve would represent an additional feature to protect the pleural space from newer contamination. In our case series, 5 patients received entirely transabdominal surgery: only 2 patients needed a thoracoscopic approach, which was performed with two supplementary thoracic operative trocars.

Laparoscopic approach also gives the chance to buttress direct suture with a gastric valve, a further and effective protection factor: on the contrary, the thoracic approach would allow to perform just a direct repair. Last but not least, laparoscopic management would be a more suitable option for all these surgical centers treating benign gastro-esophageal junction diseases (such as hiatal hernia or achalasia) rather than just high volume esophageal surgical center.

These theoretical advantages are reflected by the good postoperative outcomes of our series: even in 4 patients (57\%) emerged complications, only two of them (29\%) had > IIIA Clavien-Dindo complication (both received thoracentesis for pleural effusion). One patient died (14\%) in 11th postoperative day for cardiac failure but, as noted above, he had a critical underlying condition. Noteworthy, the length of stay is even shorter if compared with other case series reporting the thoracic approach [9, 18-22], probably as a positive effect of the mini-invasive surgery performed.

\section{Conclusions}

All this seems to support the need of further evidence prior to definitively consider the transthoracic approach as the standard of treatment: however, the very low incidence of BS does not allow comparative studies or trial to define which is the most effective and safe management with a statistical significance.

Our results support that laparoscopic approach could be an effective way to treat BS, at least when computed tomography suggests that esophageal perforation is located on the lowest portion; although our analyses have potential bias related to the retrospective, single surgeon (G.S.) and single center design of the study. Not the least, the small sample size represents a limit of our 
analysis; therefore, other case series would be helpful to better investigate this critical condition: to our knowledge, this is the largest case series reporting a not negligible number of cases treated by laparoscopic transhiatal approach, and further of these would be useful to compare abdominal and thoracic approaches.

\section{Abbreviations}

BS: Boerhaave's syndrome

\section{Acknowledgements}

None.

\section{Authors' contributions}

All authors participated in the writing of the final manuscript. All authors read and approved the final manuscript.

\section{Funding}

No funding received.

\section{Availability of data and materials}

All data generated or analyzed during this study are included in this published article.

\section{Ethics approval and consent to participate} Not applicable.

\section{Consent for publication}

All authors have read the final manuscript and agreed for its publication in the present form.

\section{Competing interests}

The authors declare that they have no competing interests.

Received: 25 May 2020 Accepted: 18 June 2020

Published online: 01 July 2020

\section{References}

1. Adams BD, Sebastian BM, Carter J. Honoring the admiral: Boerhaave-van Wassenaer's syndrome. Dis Esophagus. 2006;19(3):146-51.

2. Okamoto H, Onodera K, Kamba R, et al. Treatment of spontaneous esophageal rupture (Boerhaave syndrome) using thoracoscopic surgery and sivelestat sodium hydrate. J Thorac Dis. 2018;10(4):2206-12.

3. Turner AR, Turner SD. Boerhaave syndrome. StatPearls. Treasure Island StatPearls Publishing; 2019.

4. Han D, Huang Z, Xiang J, Li H. Hang J. The role of operation in the treatment of Boerhaave's syndrome. Biomed Res Int. 2018;2018:8483401 Published 2018 Jun 28.

5. Tellechea JI, Gonzalez JM, Miranda-García P, et al. Role of endoscopy in the management of Boerhaave syndrome. Clin Endosc. 2018;51(2):186-91.

6. Glatz T, Marjanovic G, Kulemann B, et al. Management and outcome of esophageal stenting for spontaneous esophageal perforations. Dis Esophagus. 2017:30(3):1-6.

7. Aloreidi K, Patel B, Ridgway T, Yeager T, Atiq M. Non-surgical management of Boerhaave's syndrome: a case series study and review of the literature. Endosc Int Open. 2018;6(1):E92-7.

8. Velasco Hernández DN, Horiuchi HR, Rivaletto LA, Farina F, Viscuso M. Boerhaave's syndrome with late presentation. Experience in an Argentine single center: case series. Ann Med Surg (Lond). 2019:45:59-61 Published 2019 Jul 13

9. Lawrence DR, Ohri SK, Moxon RE, Townsend ER, Fountain SW. Primary esophageal repair for Boerhaave's syndrome. Ann Thorac Surg. 1999;67(3): 818-20.

10. Jougon J, Mc Bride T, Delcambre F, Minniti A, Velly JF. Primary esophageal repair for Boerhaave's syndrome whatever the free interval between perforation and treatment. Eur J Cardiothorac Surg. 2004;25(4):475-9.

11. Nakano T, Onodera K, Ichikawa $\mathrm{H}$, et al. Thoracoscopic primary repair with mediastinal drainage is a viable option for patients with Boerhaave's syndrome. J Thorac Dis. 2018;10(2):784-9.
12. Aref $H$, Yunus $T$, Alhallaq O. Laparoscopic management of Boerhaave's syndrome: a case report with an intraoperative video. BMC Surg. 2019;19(1): 109 Published 2019 Aug 13.

13. Hayakawa S, Mitsui A, Kato Y, et al. Laparoscopic transhiatal suture closure for spontaneous esophageal rupture: a case report. Surg Case Rep. 2019; 5(1):149.

14. Chirica M, Kelly MD, Siboni S, et al. Esophageal emergencies: WSES guidelines. World J Emerg Surg. 2019;14:26 Published 2019 May 31.

15. Korn $\mathrm{O}$, Oñate JC, López R. Anatomy of the Boerhaave syndrome. Surgery. 2007;141(2):222-8.

16. Curci JJ, Horman MJ. Boerhaave's syndrome: The importance of early diagnosis and treatment. Ann Surg. 1976;183(4):401-8.

17. Pezzetta E, Kokudo T, Uldry E, et al. The surgical management of spontaneous esophageal perforation (Boerhaave's syndrome) - 20 years of experience. Biosci Trends. 2016:10(2):120-4.

18. Hill AG, Tiu AT, Martin IG. Boerhaave's syndrome: 10 years experience and review of the literature. ANZ J Surg. 2003;73(12):1008-10.

19. Prichard R, Butt J, Al-Sariff N, et al. Management of spontaneous rupture of the oesophagus (Boerhaave's syndrome): single centre experience of 18 cases. Ir J Med Sci. 2006;175(4):66-70.

20. Lázár G Jr, Paszt A, Simonka Z, Bársony A, Abrahám S, Horváth G. A successful strategy for surgical treatment of Boerhaave's syndrome. Surg Endosc. 2011;25(11):3613-9.

21. D'Journo XB, Doddoli C, Avaro JP, et al. Long-term observation and functional state of the esophagus after primary repair of spontaneous esophageal rupture. Ann Thorac Surg. 2006;81(5):1858-62.

22. Shen G, Chai Y, Zhang GF. Successful surgical strategy in a late case of Boerhaave's syndrome. World J Gastroenterol. 2014:20(35):12696-700.

\section{Publisher's Note}

Springer Nature remains neutral with regard to jurisdictional claims in published maps and institutional affiliations.

Ready to submit your research? Choose BMC and benefit from

- fast, convenient online submission

- thorough peer review by experienced researchers in your field

- rapid publication on acceptance

- support for research data, including large and complex data types

- gold Open Access which fosters wider collaboration and increased citations

- maximum visibility for your research: over $100 \mathrm{M}$ website views per year

At $\mathrm{BMC}$, research is always in progress.

Learn more biomedcentral.com/submissions 